\title{
Mimickers of novel coronavirus disease 2019 (COVID-19) on chest CT: spectrum of CT and clinical features
}

\author{
Ali H. Elmokadem ${ }^{1,2^{*}} \mathbb{B}$, Nihal M. Batouty ${ }^{1}$, Dalia Bayoumi ${ }^{1}$, Basma N. Gadelhak' ${ }^{1}$, Rihame M. Abdel-Wahab', \\ Mona Zaky', Sherif A. Abo-Hedibah²,3, Ahmed Ehab ${ }^{4,5}$ and Ahmed El-Morsy ${ }^{1}$
}

\begin{abstract}
COVID-19 (coronavirus disease 2019) is a recently emerged pulmonary infection caused by severe acute respiratory syndrome coronavirus (SARS-CoV-2). It started in Wuhan, China, in December 2019 and led to a highly contagious disease. Since then COVID-19 continues to spread, causing exponential morbidity and mortality and threatening economies worldwide. While the primary diagnostic test for COVID-19 is the reverse transcriptase-polymerase chain reaction (RT-PCR) assay, chest $C T$ has proven to be a diagnostic tool of high sensitivity. A variety of conditions demonstrates $C T$ features that are difficult to differentiate from COVID-19 rendering CT to be of low specificity. Radiologists and physicians should be aware of imaging patterns of these conditions to prevent an erroneous diagnosis that could adversely influence management and patients' outcome. Our purpose is to provide a practical review of the conditions that mimic COVID-19. A brief description of the forementioned clinical conditions with their CT features will be included.
\end{abstract}

Keywords: Computed tomography, Differential diagnosis, Coronavirus disease 2019, COVID-19, SARS-COV2

\section{Key points}

- Categorizing COVID-19 mimickers according to chest $\mathrm{CT}$ features.

- Review of clinical and chest CT characteristics of COVID-19 mimickers.

- Differentiation between COVID-19 and other mimickers.

\section{Background}

Severe acute respiratory syndrome coronavirus-2 (SARS-CoV-2) is a new type of coronavirus that was isolated from respiratory tract samples in the city of Wuhan, Hubei Province, China, in December 2019 [1].

\footnotetext{
*Correspondence: mokadem83@yahoo.com

1 Department of Radiology, Mansoura University, Elgomhoria St., Mansoura 35516, Egypt

Full list of author information is available at the end of the article
}

COVID-19 (coronavirus disease 2019) became a highly infectious disease that was officially recognized as a pandemic in March 2020 [2]. More than 49 million patients and 1.2 million deaths of COVID-19 have been reported worldwide by November 10, 2020 [3]. During the rapid spread of SARS-COV-2 globally, diagnostic methods for detecting the virus have many limitations. RT-PCR testing has low sensitivity early in the disease (ranging from 37 to $71 \%$ ) [4]. CT chest has high sensitivity, but low specificity [4-7]. This low specificity may stem from the fact that it is difficult to distinguish COVID-19 from other diseases on chest CT [8].

In order to optimize patient management, medical care and disease control, radiologists and chest physicians should be aware of CT chest features that distinguish COVID-19 from other etiologies [9]. The aim of the review is to differentiate between the COVID-19 findings on $\mathrm{CT}$ and other mimickers. 


\section{COVID-19}

Patients infected with COVID-19 usually presents with fever (88.7-98\%), cough (67.8-76\%) and dyspnea (55\%), less commonly headache, fatigue, hemoptysis conjunctival congestion and loss of smell $[10,11]$. Abdominal symptoms such as nausea, vomiting and diarrhea are possible [11]. The disease can progress to acute respiratory distress syndrome, metabolic acidosis, septic shock, coagulation dysfunction and multi-organ failure [12]. Laboratory findings in COVID-19 are a decreased lymphocyte count and an increased CRP and high-sensitivity C-reactive protein level [10-12]. Lymphopenia was reported to be a dependable indicator to categorize the moderate, severe, and critical ill types [13].

COVID-19 patients are classified as having minimal, common, severe and critical illness [12]. Minimal disease patients have subtle clinical symptoms. Common cases have symptoms such as fever and mild coughing. Severe cases are the ones meet any of the following criteria: (1) resting blood oxygen saturation $\leq 93 \%$; (2) respiratory rate $\geq 30$ beats/min; or (3) oxygen concentration $\leq 300 \mathrm{mmHg}$. Critical patients can be affected with one of the following: (1) respiratory failure needing mechanical ventilators; (2) shock; and (3) organ failure requiring intensive care management.

Ground-glass (GGO) pattern with or without consolidation is the most common feature of COVID-19 infections. They are usually bilateral, multifocal and peripheral with posterior or lower lung zone distribution $[6,7$, 14-16]. Ground-glass opacification is defined as hazy increased lung opacity with preserved bronchovascular margins contrary to consolidation that is defined as a homogeneously increased parenchymal attenuation with obscuration of margins of airway and vessel walls [14]. A different unifocal pattern of GGO was reported by Zhou, et al. in early phase of disease, commonly at the inferior lobe of right lung [17]. Furthermore, Bernheim, et al. reported a significant number of cases having opacities of non-specific distribution and non-predominant perihilar pattern [6]. GGO has also been frequently reported to have a "crazy paving" pattern $[6,7,14,18]$ that is defined as thickening of interlobular septa and intralobular lines with superimposed GGO [17, 19]. Vascular dilatation and traction bronchiectasis are typical findings found in the GGO detected in COVID-19 patients [20]. Architectural distortion with the formation of subpleural bands was reported in some cases during a peak stage of the disease [9]. Pulmonary embolism was found among patients with COVID-19 and was linked to elevated D-dimer [21]. Other findings typically were seen in infection as thickening of bronchial wall, mucoid impactions and centrilobular nodules (tree-in-bud), and lymphadenopathy and pleural effusion are rarely observed $[6,14]$. Figures 1,2 and 3, and Additional file 1 demonstrate typical CT features of COVID-19 pneumonia.

CT Findings in patients with COVID-19 vary according to the timing of imaging. A negative $\mathrm{CT}$ during first two days after onset of symptoms with GGO usually develops between first and fourth days after symptom onset with the peak at 6-13 days have been reported [6, $9,18,22]$. The frequency of consolidation, mixed patterns and reversed halo increases later in the disease $[6,9,18]$.

The Radiological Society of North America expert consensus proposed four categories to report chest CT findings attributed to COVID-19 (typical, indeterminate, atypical and negative for pneumonia) [11]. Based on this classification, we categorized the mimics into three categories (Table 1): The first and second category based only on similarity to the imaging features of COVID-19 regardless of the differences in clinical course and the third category based on similarity to COVID-19-related clinical manifestations.

(1) CT mimickers of typical COVID-19 that displays bilateral, peripheral GGO or multifocal rounded GGO of rounded morphology with or without consolidation, "crazy-paving" pattern or reversed halo sign.

(2) CT mimickers of indeterminate COVID-19 that manifests as multifocal, diffuse, perihilar or unilateral GGO with or without consolidation, non-specific distribution or non-rounded GGO.

(3) Conditions presented by clinical scenarios that mimic COVID-19 but with atypical CT features such as lobar or segmental consolidation without GGO, pulmonary nodules (centrilobular or "tree in-bud"), pulmonary cavitation, smooth interlobular septal thickening, pleural effusion and lymphadenopathy. Table 2 summarizes the CT findings, extra-pulmonary manifestation and laboratory findings of COVID-19 and mimickers.

\section{Chest CT mimickers of typical COVID-19 Viral pneumonias}

Viruses are considered the most common pathogens causing acute respiratory tract infections [23] usually, the clinical signs and symptoms of viral pneumonia are non-specific, and the clinical course vary according to patient age and immune status [24]. CT features of viral pneumonia are variable and may be affected by immunity and pathophysiology of the virus [23]. Differentiating between COVID-19 and non-COVID19 pneumonia is a crucial need in the current situation to reduce unnecessary quarantine for suspected patients. Bai et al. [9] 

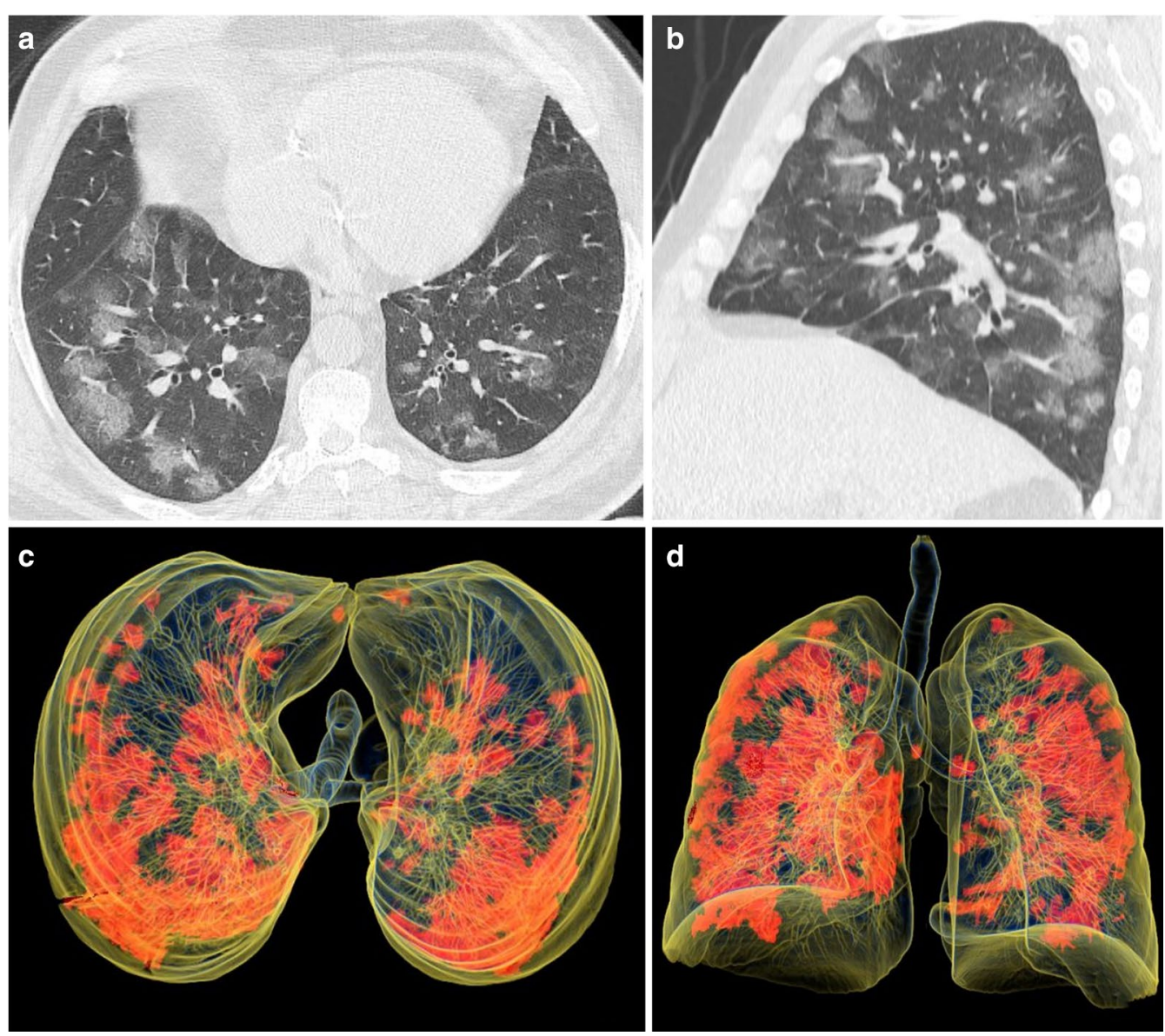

Fig. 1 Typical CT imaging features for COVID-19. a, b A 54-year-old man with positive RT-PCR test, axial and sagittal reformatted CT images shows multifocal rounded GGO with predominant peripheral distribution. $\mathbf{c}$, $\mathbf{d}$ Three-dimensional semitransparent volume-rendered reconstructions show the peripheral and basal distribution of the ground-glass opacities across both lungs

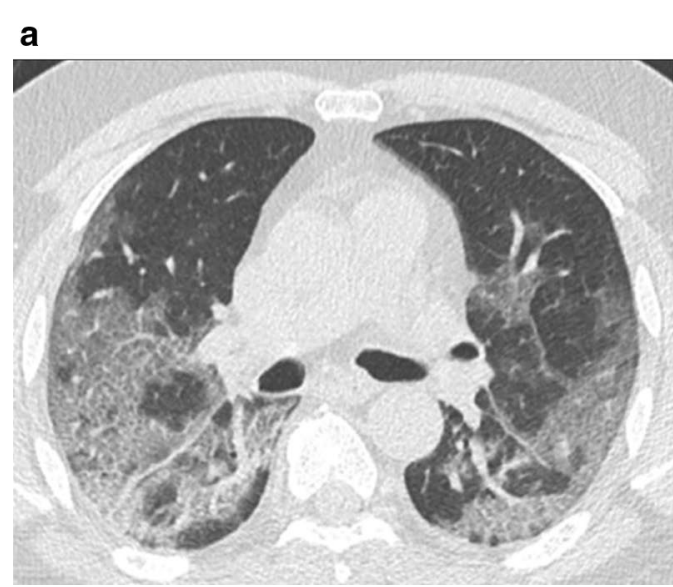

\section{b}

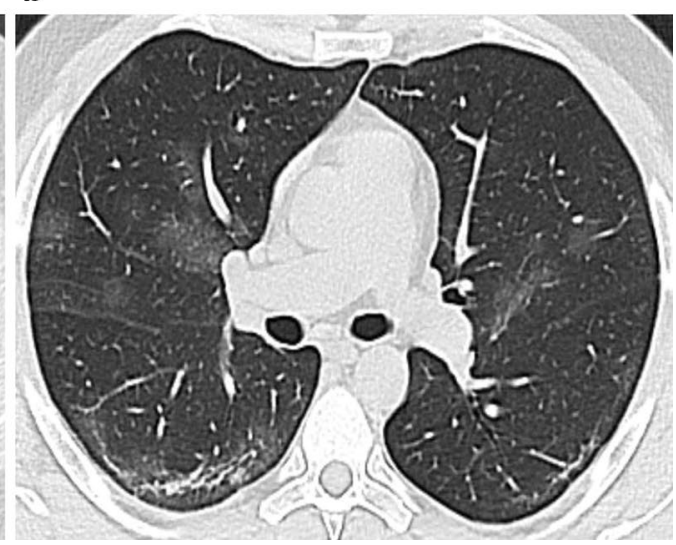

Fig. 2 Typical CT imaging features for COVID-19. a A 72-year-old woman with positive RT-PCR test, axial CT image shows multifocal peripheral GGO with superimposed interlobular septal thickening and visible intralobular lines ("Crazy-paving"). b A 46-year-old man with a positive RT-PCR, axial CT image shows bilateral multifocal rounded and peripheral GGO with bilateral posterior subpleural bands 


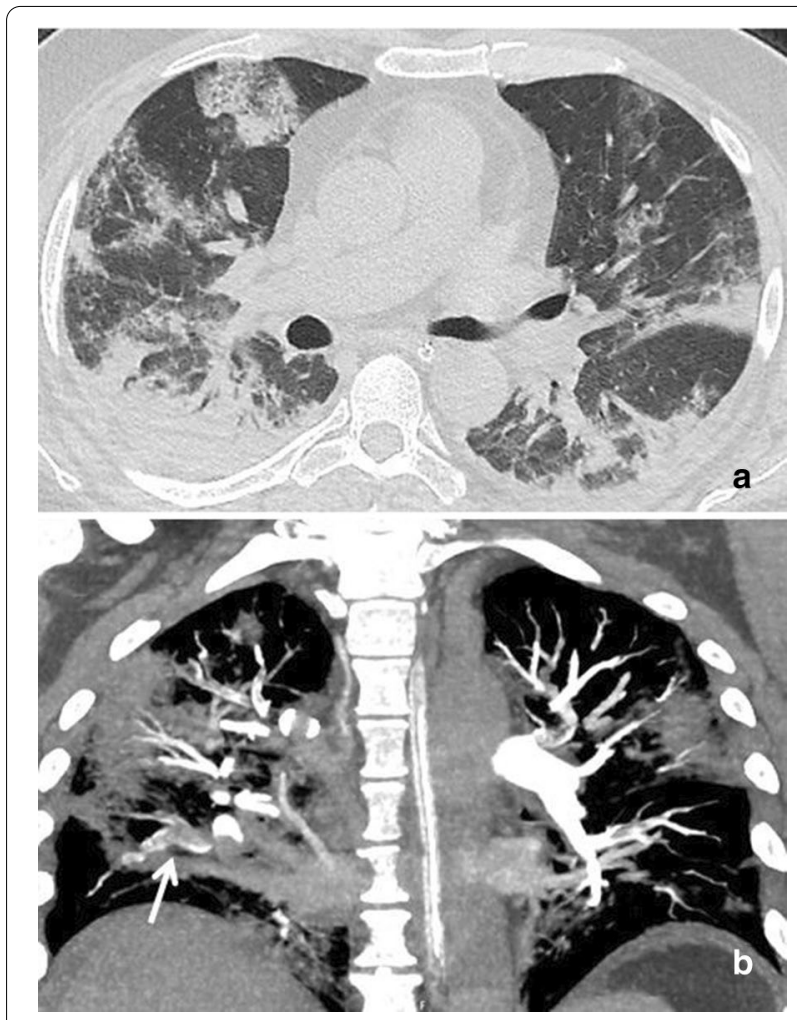

Fig. 3 A 50-year-old man with a positive RT-PCR. a Axial CT image shows moderate COVID-19 pneumonia manifested by peripherally located GGO and consolidations. b Coronal pulmonary CT angiogram shows multiple filling defects in segmental and subsegmental pulmonary artery branches, clearly seen in the right inferior pulmonary branches (white arrow)

demonstrate that radiologists are capable of distinguishing COVID-19 from other viral etiologies of pneumonia on chest CT with high specificity (93-100\%).

HPIV (human parainfluenza virus) presents on CT as multifocal patchy consolidation with GGO of non-specific distribution and in one-fourth of patients show centrilobular nodules with bronchial wall thickening [25].

Influenza $A, B$ and $C$ pneumonia (Fig. 4) manifested on CT as focal, multifocal, or diffuse GGO with areas of consolidation. Unlike COVID-19, centrilobular nodules, pseudocavitation, pneumatocele formation and lymphadenopathy are commonly seen. Pleural effusion and cavitation can develop later in the course of the disease [23, 24]. An H1N1 (a subtype of Influenza A) pandemic reported in more than 70 countries with 30,000 cases of infection occurred in 2009 [26].

Corona virus cause pneumonia, bronchiolitis and even acute respiratory distress syndrome (ARDS). SARS Coronavirus (severe acute respiratory syndrome) outbreak originated from Guangdong Province, China, occurred during 2002-2003 [27]. In 2012, another coronavirus-related epidemic occurred in the Middle East, identified as MERS (Middle East respiratory syndrome) [27]. CT features of both diseases are similar to COVID-19 pneumonia including multifocal GGOs with less common consolidations. Reticulation is noted after the second week. Cavitation, lymphadenopathy or pleural effusion are not common findings [23].

\section{Organizing pneumonias (OP)}

Cryptogenic organizing pneumonia (COP) is a disease of unknown etiology previously named bronchiolitis obliterans organizing pneumonia (BOOP). It is commonest among the 55-60 age groups and it usually presents with a several-month history of nonproductive cough, lowgrade fever, malaise and shortness of breath in contrary to the rapidly progressive course of COVID-19. COP can be caused by different infective and non-infective causes and results in bronchiolar occlusion [28]. On CT, COP usually shows multifocal GOO or consolidations predominantly subpleural and peribronchial distribution. Less commonly, CT includes variable-sized solid nodules with peribronchial or peribronchiolar distribution with architectural distortion and interlobular septal thickening [29]. COP is characterized by areas of clearing consolidation with central ground-glass density, which are known as the reversed halo sign or "atoll sign" (Fig. 5); however, these signs are only seen in less than $20 \%$ of patients $[28,29]$. Reversed halo sign can also be secondary to other causes such as pulmonary mucormycosis, invasive pulmonary aspergillosis, pulmonary infarction due to venous thromboembolism, granulomatosis with polyangiitis, sarcoidosis, lymphomatoid granulomatosis and lipoid pneumonitis. It is uncommon feature for COVID-19 but possible finding that occurs later with disease progression.

\section{Connective tissue disease (CTD)-associated pneumonias:}

Rheumatoid arthritis (RA), systemic sclerosis, scleroderma, polymyositis or dermatomyositis, systemic lupus erythematosus and Sjögren's syndrome can all be associated with the development of interstitial lung disease. RA is the commonest among the aforementioned disease and is characterized by subacute or chronic inflammatory polyarthropathy. Parenchymal affection in rheumatoid patients has two common types, usual interstitial pneumonia (UIP) pattern and non-specific interstitial pneumonia (NSIP) pattern [30]. Other less common patterns may happen as OP and obliterative bronchiolitis that may simulate COVID-19 on chest CT; however, the clinical course is different considering the gradual progressive course of CTD-associated pneumonias. The overlap between it manifests on $\mathrm{CT}$ by extensive GGO and 
Table 1 Proposed reporting categories for CT findings related to COVID-19 [11]

\begin{tabular}{|c|c|c|}
\hline $\begin{array}{l}\text { COVID-19 pneumonia } \\
\text { Imaging classification }\end{array}$ & CT findings & Differential diagnosis \\
\hline CT mimickers of typical COVID-19 & Typical findings are: & 1. Influenza pneumonia \\
\hline $\begin{array}{l}\text { Commonly reported imaging features of greater } \\
\text { specificity for COVID-19 pneumonia }\end{array}$ & $\begin{array}{l}\text { 1. Peripheral, bilateral, GGO with or without } \\
\text { consolidation or crazy-paving } \\
\text { 2. Multifocal GGO of rounded morphology with } \\
\text { or without consolidation or crazy-paving } \\
\text { 3. Reverse halo sign or other findings of organ- } \\
\text { izing pneumonia }\end{array}$ & $\begin{array}{l}\text { 2. SARS and MERS pneumonia } \\
\text { 3. Organizing pneumonia } \\
\text { 4. Connective tissue disease (RA) } \\
\text { 5. Drug toxicity } \\
\text { 6. Acute interstitial pneumonia }\end{array}$ \\
\hline CT mimickers of indeterminate COVID-19 & Absence of typical features AND presence of: & 1. Other causes of viral pneumonia \\
\hline $\begin{array}{l}\text { Commonly reported imaging features of greater } \\
\text { specificity for COVID-19 pneumonia }\end{array}$ & $\begin{array}{l}\text { 1. Multifocal, diffuse, perihilar or unilateral GGO } \\
\text { with or without consolidation } \\
\text { 2. Lacking of specific distribution } \\
\text { 3. Non-rounded or non-peripheral GGO }\end{array}$ & $\begin{array}{l}\text { 2. Atypical bacterial infections } \\
\text { 3. Pneumocystis infection } \\
\text { 4. Pulmonary edema } \\
\text { 5. ARDS } \\
\text { 6. Acute hypersensitivity pneumonitis, } \\
\text { 7. Eosinophilic pneumonia } \\
\text { 8. Diffuse alveolar hemorrhage } \\
\text { 9. Pulmonary alveolar proteinosis }\end{array}$ \\
\hline $\begin{array}{l}\text { Conditions presented by clinical scenarios that } \\
\text { mimic COVID-19 but with atypical CT features } \\
\text { Uncommonly or not reported CT features }\end{array}$ & $\begin{array}{l}\text { Absence of typical or indeterminate features AND } \\
\text { presence of: } \\
\text { 1. Isolated lobar or segmental consolidation } \\
\text { without GGO } \\
\text { 2. Discrete small nodules (centrilobular or "tree } \\
\text { in-bud") } \\
\text { 3. Lung cavitation } \\
\text { 4. Smooth interlobular septal thickening with } \\
\text { pleural effusion }\end{array}$ & $\begin{array}{l}\text { Alternative diagnoses rather than COVID-19 } \\
\text { should be considered such as typical bacte- } \\
\text { rial pneumonia, TB or other non-infective } \\
\text { processes }\end{array}$ \\
\hline
\end{tabular}

patchy mosaic perfusion (Fig. 5), solid nodules, discrete cysts, air trapping and segmental consolidations [31].

NSIP occurs more commonly in association with other connective tissue diseases such as scleroderma and polymyositis or dermatomyositis interstitial lung disease (PM/DM ILD). The most characteristic CT finding in NSIP is GGO, which is usually bilateral and symmetric with lower lobe predominance. Other common CT findings include traction bronchiectasis, fine reticulation and volume loss of lower lobes. Unlike COVID-19, subpleural sparing of the posterior regions of the lower lobes and mediastinal lymph node enlargement are relatively common features in NSIP [31]. Furthermore, consolidation is not a common finding in NSIP and only seen when it is superimposed with organizing pneumonia.

\section{Drug induced acute lung injury}

Drug toxicity is a common and underdiagnosed cause of acute lung disease. Radiologic features and clinical symptoms of drug-induced lung injury differ according to the histopathological pattern of affection. The histopathologic manifestations that could simulate COVID-19 disease include diffuse alveolar damage (DAD) and OP.

Bleomycin, busulfan, carmustine, cyclophosphamide, mitomycin, melphalan and gold salts are the most common drugs that cause DAD [32], while drugs that most commonly induce OP are bleomycin, gold salts, methotrexate and cyclophosphamide (Fig. 5) [32, 33]. Recently, a crucial side effect has arisen as a lung-specific toxicity caused by an epidermal growth factor receptor (EGFR) tyrosine kinase inhibitors (TKIs) for the treatment of non-small cell lung cancer (NSCLC) [33]. Fibrosis can regress significantly, remain stable, or evolve to honeycomb lung based on the severity of the lung injury [34].

\section{Diffuse alveolar damage (DAD)/acute interstitial pneumonia (AIP)}

Acute interstitial pneumonia is rapidly progressive pneumonia that occurs in an otherwise healthy person over a few days to weeks [31]. It is indistinguishable both clinically and histologically from ARDS. AIP occurs in wide age range (mean age 50 years) [35]. CT findings of AIP are similar to those of ARDS and the sever form of COVID19, though AIP more often produces symmetric and bilateral GGO more commonly in the lower lobes with the tendency to spare the costophrenic recesses crazy paving pattern is occasionally present. Areas of consolidation predominantly located in the dependent portions but less extensive than GOO. The delayed fibrotic phase of DAD simulates UIP (Fig. 6), and it is associated with architectural distortion, traction bronchiectasis and honeycombing [31, 35]. 


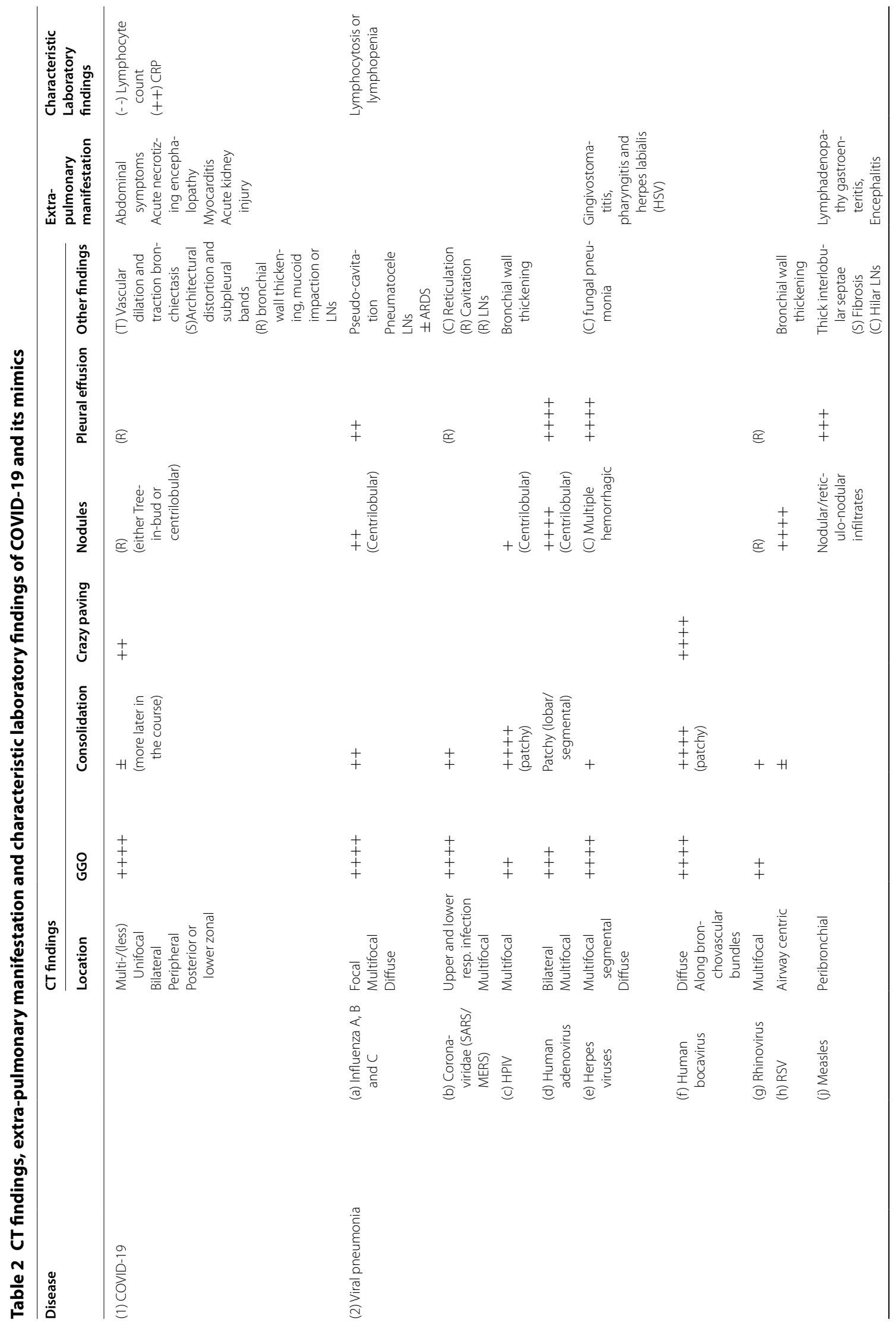




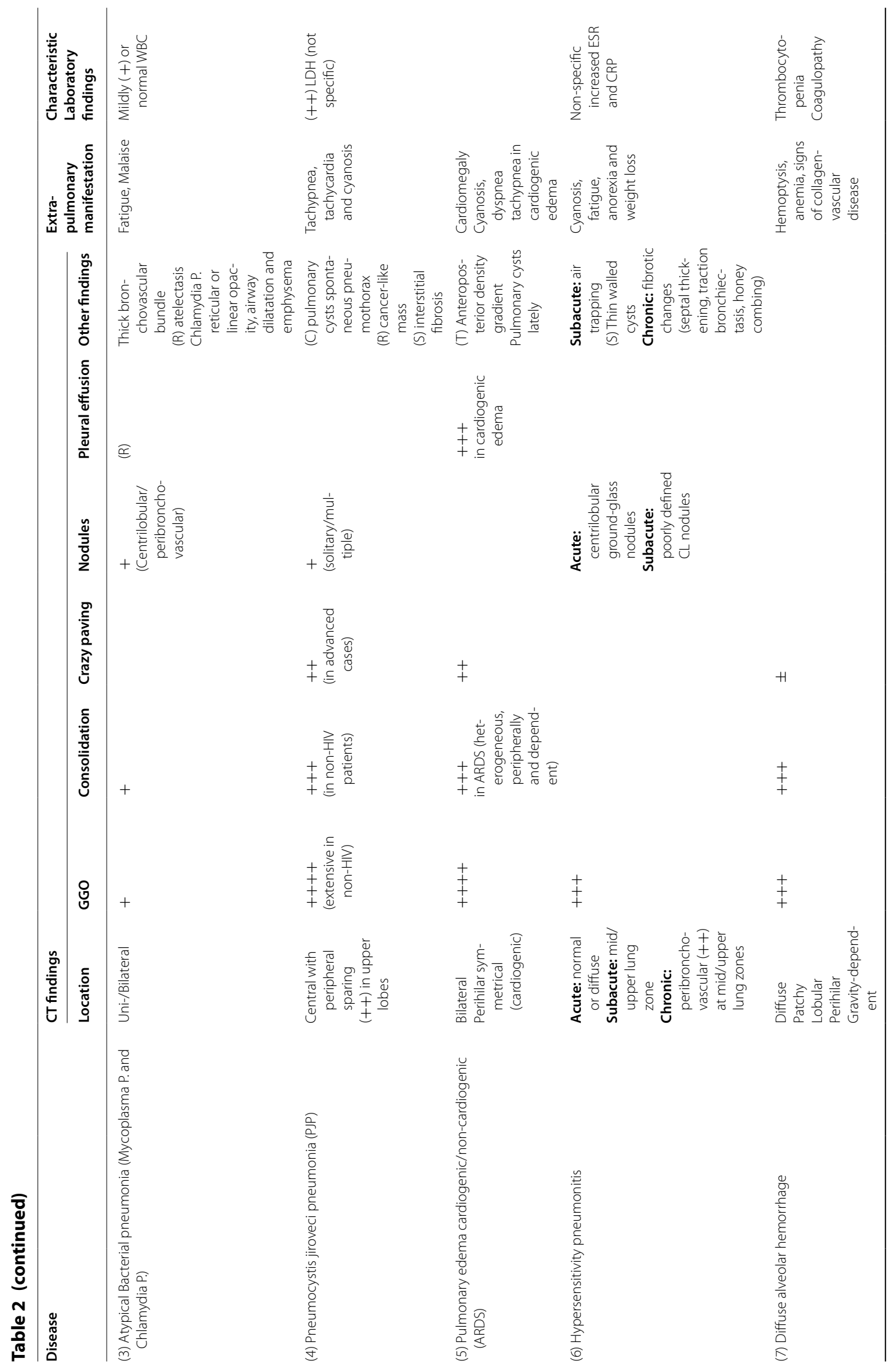




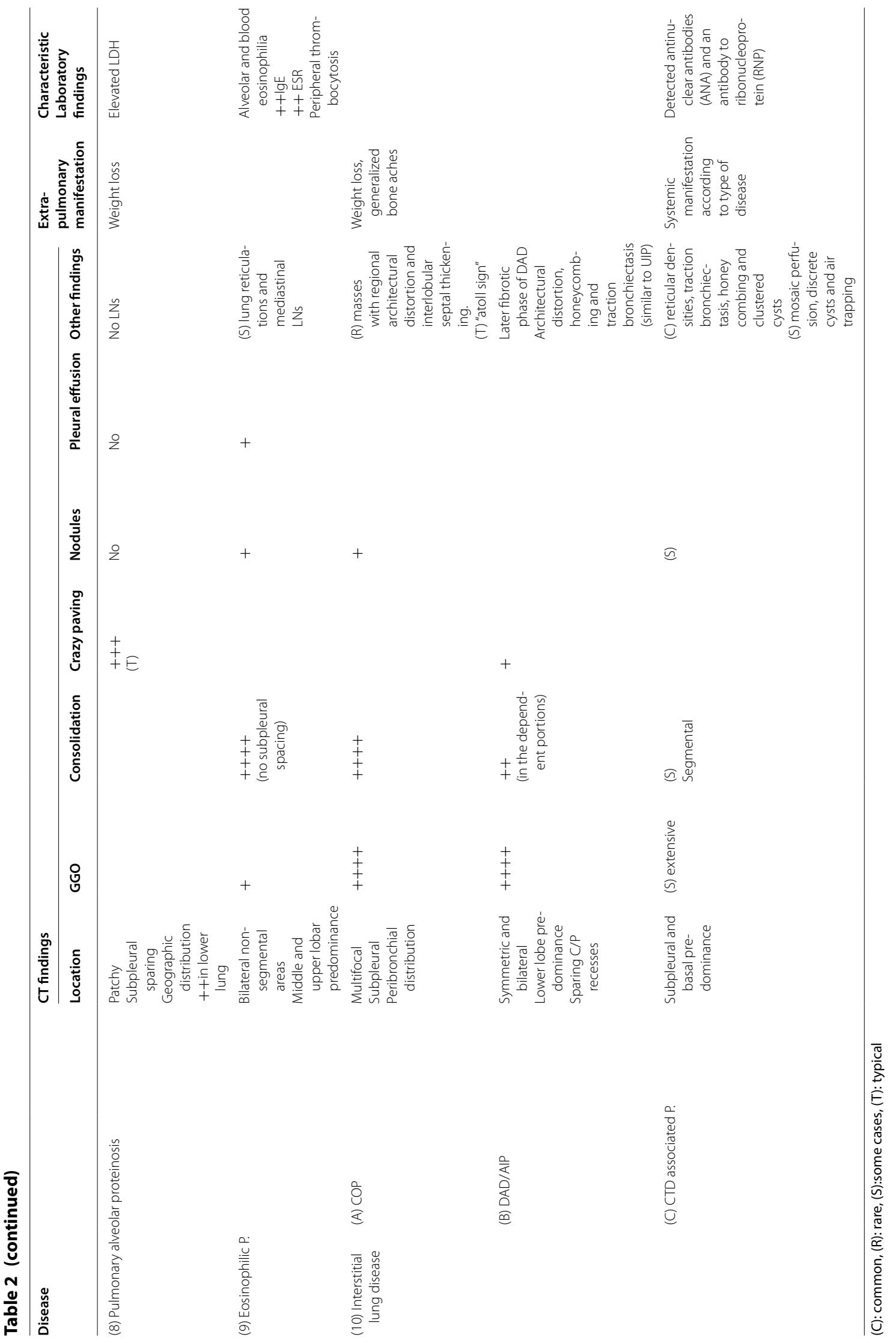



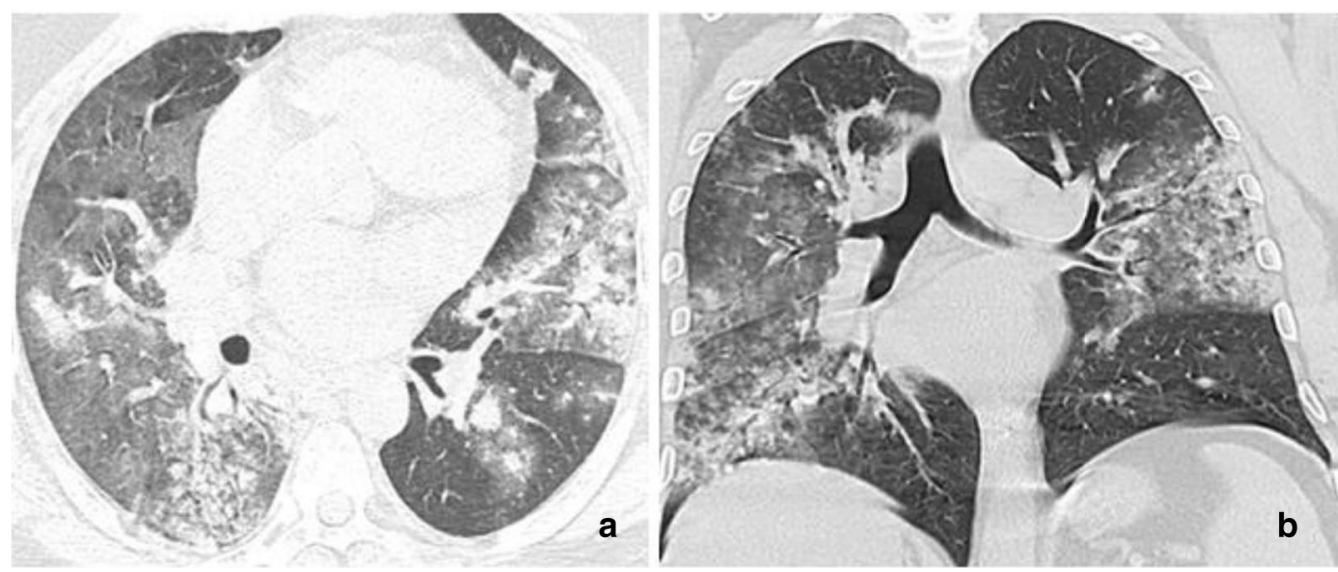

Fig. 4 Viral infection mimicking typical COVID-19. a, b Axial and coronal reformatted CT image obtained for a 52-year-old man with positive PCR test for influenza (a) pneumonia show diffuse and multifocal GGO with peripheral consolidation and centrilobular nodules scattered in both lungs
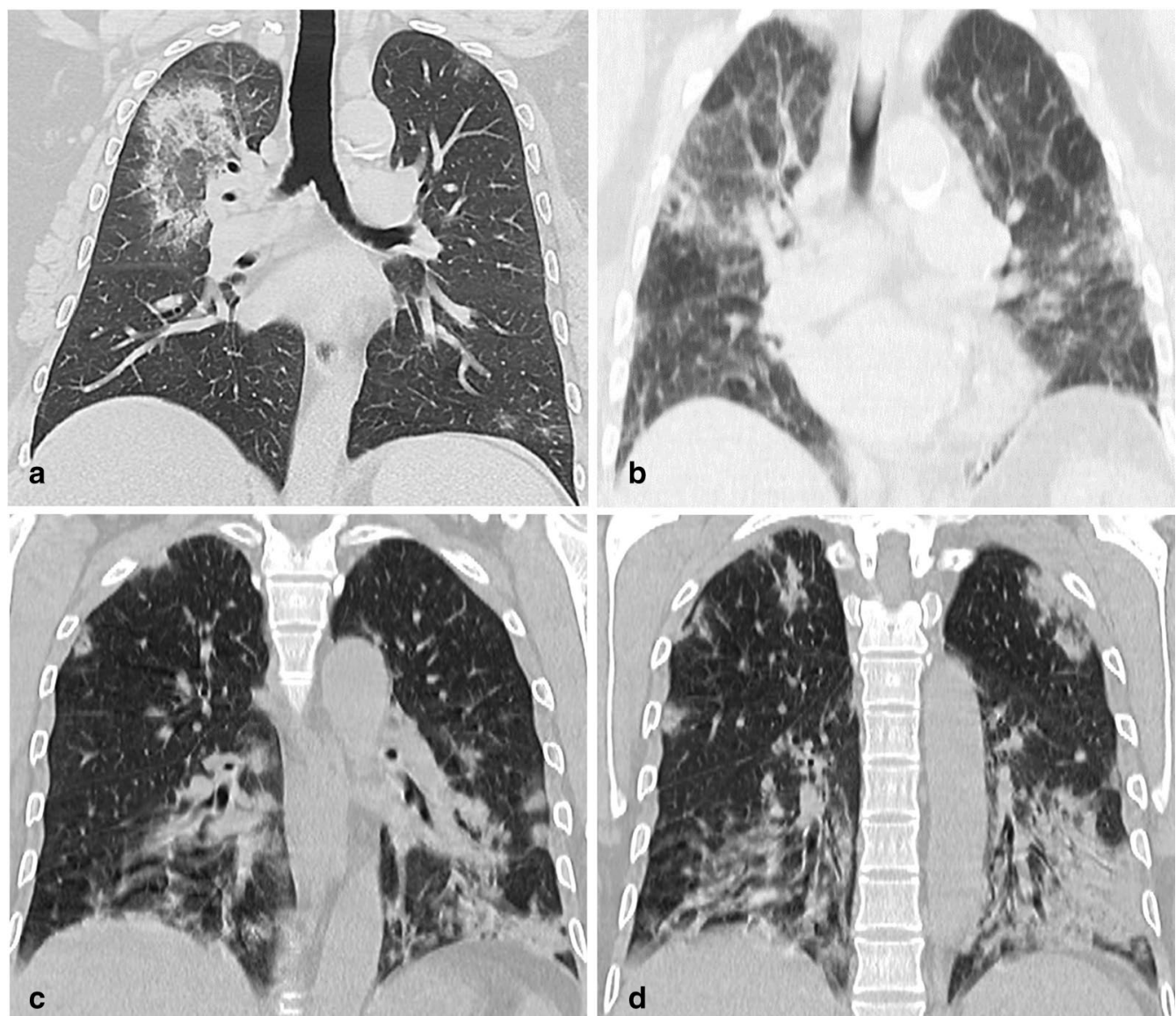

Fig. 5 Organizing pneumonia mimicking typical COVID-19. a Cryptogenic organizing pneumonia in a 55-year-old man with history of chest infection not responding to multiple courses of antibiotics, coronal reformatted CT image shows reversed halo sign in the right lung with small areas of GGO in the left lung. Transbronchial biopsy showed findings of COP. $\mathbf{b}$ Rheumatoid arthritis induced interstitial pneumonia in a 67-year-old woman, coronal reformatted CT image shows bilateral ground-glass opacities with interlobular and interstitial thickening. $\mathbf{c}$, $\mathbf{d}$ Cyclophosphamide-induced OP in a 56-year-old man with Hodgkin disease, coronal reformatted CT images show peripheral multifocal areas of poorly defined focal consolidation, small areas of GGO and bronchial wall thickening 

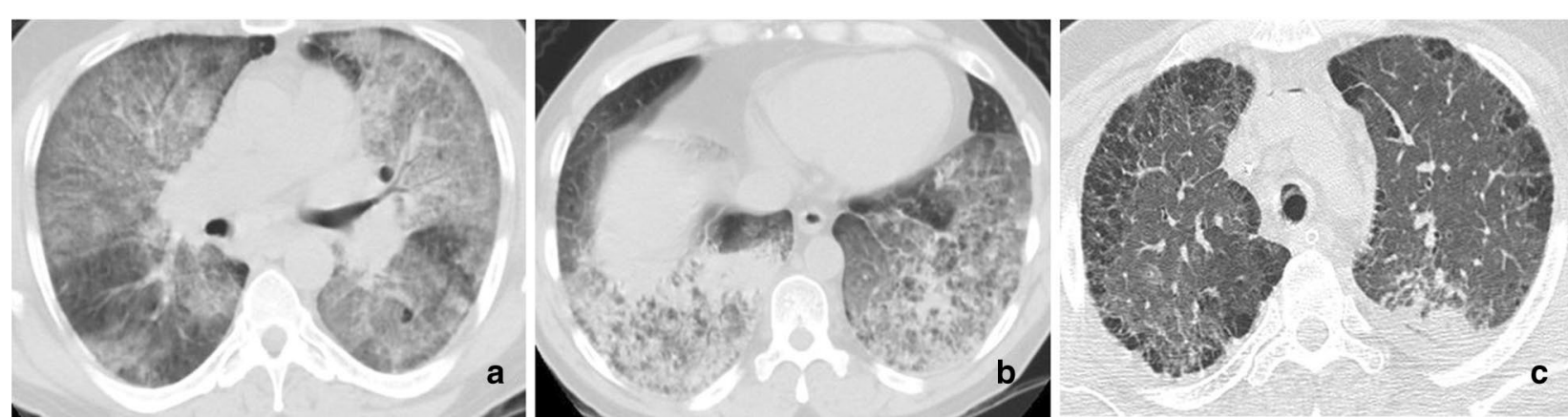

Fig. 6 Acute interstitial pneumonia mimicking typical COVID-19 in a 48-year-old man presented with symptoms simulating ARDS. $\mathbf{a}$, b axial CT images show bilateral extensive diffuse GGO and few areas of consolidation with interlobular and intralobular septal thickening, and mild bronchial dilatation. Transbronchial biopsy showed features of diffuse alveolar damage. c Follow-up axial CT image shows after one month shows subpleural honeycombing, fibrotic bands and traction bronchiectasis

\section{Chest CT mimickers of indeterminate COVID-19}

\section{Viral pneumonias}

Viral pneumonia may have CT features mimicking indeterminate COVID-19 (Fig. 7) including perihilar distribution, centrilobular/tree in pud nodules, pleural thickening, effusion or lymphadenopathy.

Human Adenovirus pneumonia shows bilateral multifocal GGO with patchy consolidations and may show lobar or segmental distribution unlike COVID-19. Centrilobular nodules and pleural effusion are common [23].

Herpes viruses include HSV types 1 and 2 and CMV. A predominantly multifocal segmental or diffuse GGO is a common feature of herpes pneumonia, consolidation is less evident [24]. The presence of multiple hemorrhagic nodules, associated fungal pneumonia or pleural effusion is frequent with HSV infection $[23,25]$.

Human bocavirus manifests as diffuse GGO or patchy consolidation along bronchovascular bundles associated with interlobular septal thickening [23].

Rhinovirus $A, B$ and $C$ severe pneumonia characterized by bilateral patchy consolidations with multifocal GOO and interlobular septal thickening [36]

\section{Atypical bacterial pneumonias}

Mycoplasma (M) pneumonia and chlamydia (C) pneumonia are known as atypical pneumonia, patients present with dry or productive cough, fatigue and malaise with mildly elevated or normal white blood cell count [37, 38]. Both $C$ pneumoniae pneumonia and $M$ pneumonia (Fig. 8) cause infectious bronchiolitis or bronchopneumonia that may simulate COVID-19 as they are presented with unilateral or bilateral areas of consolidation or GGO and thickened broncovascular bundle [37]. However, the presence of centrilobular or peribronchovascular nodules may help in differentiation from COVID-19. Pleural effusion and atelectasis are less frequent features. $\mathrm{C}$ pneumonia had a higher frequency of reticular or linear opacity, airway dilatation and pulmonary emphysema that represent its chronic nature [38].

\section{Pneumocystis jirovecii pneumonia (PJP)}

Pneumocystis jirovecii is an atypical fungus that causes pneumonia in immunocompromised patients [39]. The presentation of PJP in a patient with HIV infection typically is subacute, characterized by a gradual onset (over 1 month duration) of dry cough and dyspnea with signs of respiratory compromise, including tachycardia, tachypnea and cyanosis [40]. On CT, extensive GGO is the principal finding in PJP (Fig. 8). In HIV-related PJP, CT shows commonly central distribution of GGO with relative peripheral sparing and predilection for the upper lobes. CT in non-HIV patients shows a greater extent of GGO with more common and rapidly developing lung consolidation [39, 40]. In advanced disease, crazy paving pattern and consolidation are noted. Interstitial fibrosis may occur in patients recovering from PJP, thus known as chronic Pneumocystis pneumonia [39].

\section{Pulmonary edema}

Pulmonary edema has various types and etiologies with different radiological patterns: cardiogenic pulmonary edema (e.g., congestive heart failure), non-cardiogenic pulmonary edema and fluid overload (e.g., renal failure) [41]. Both pulmonary edema and COVID 19 infection may have bilateral GGO but with different distribution and other associated signs. The diffuse ground-glass pattern of cardiogenic pulmonary edema tends to be perihilar, bilateral and symmetrical (Fig. 9). Cardiogenic pulmonary edema is presented by acute dyspnea, associated with cardiomegaly and pleural effusion is common, while ARDS has dense-dependent consolidations, with or without interlobular septal thickening, and pleural 

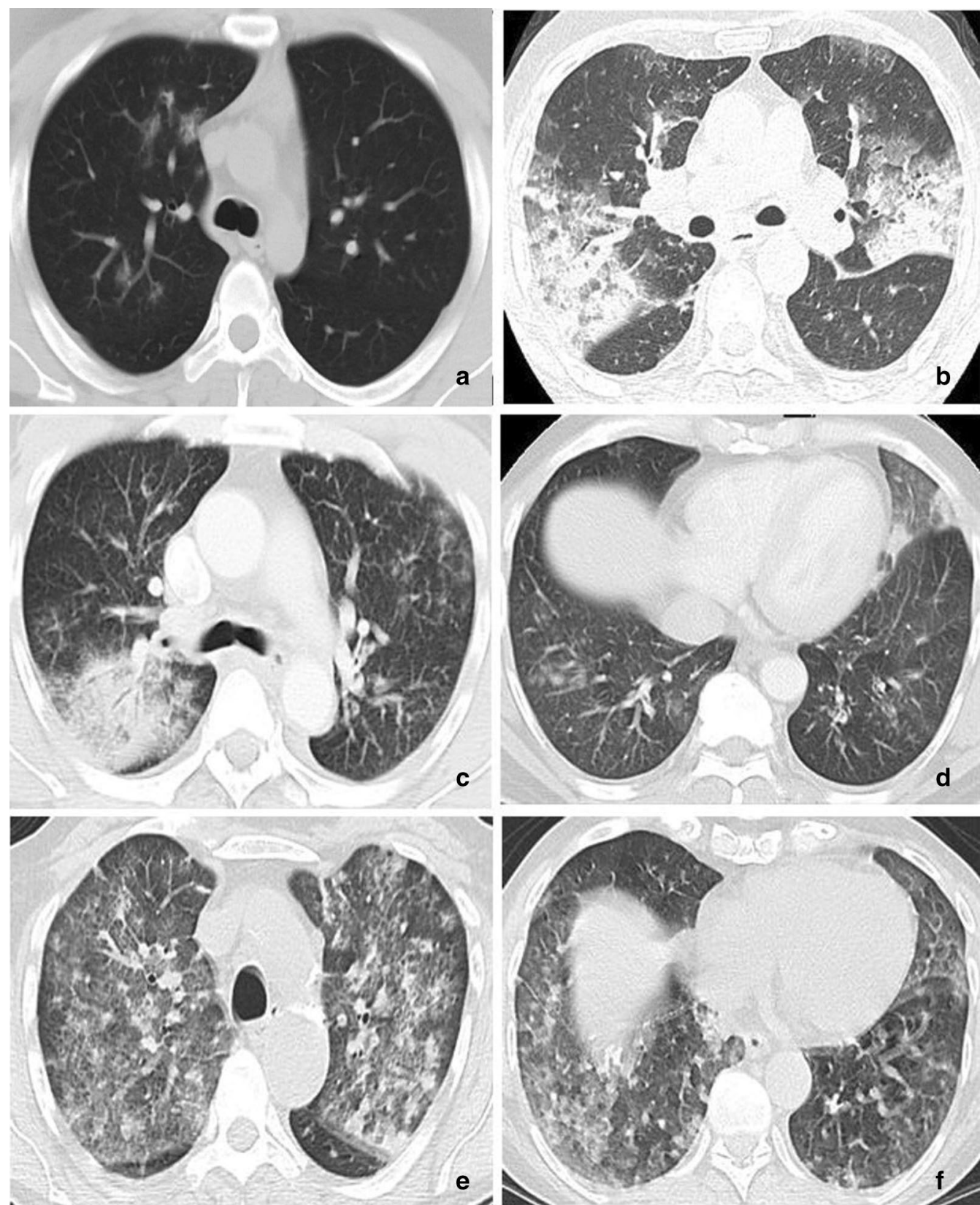

Fig. 7 Indeterminate COVID-19 and viral pneumonia mimickers. a, b Indeterminate CT features for COVID-19 in two different patients with positive RT-PCR test, axial CT images show unilateral small areas of non-peripheral GGO (a) and bilateral multifocal non-rounded GGO of non-specific distribution (b). $\mathbf{c}$, d Adenovirus pneumonia in a 48-year-old man, axial CT images show bilateral area of consolidation with nearby GGO and bilateral centrilobular nodules. e, $\mathbf{f}$ HSV pneumonia in a 75-year-old woman, axial CT images show widespread bilateral GGO of non-rounded morphology, small areas of consolidation and diffuse interlobular septal thickening

effusion may occur $[41,42]$. Pulmonary edema can also be presented by crazy paving pattern [42].

\section{Acute respiratory distress syndrome (ARDS)}

ARDS in adults is a non-specific catastrophic response of the lung to injury. Pneumonia, aspiration of gastric contents, toxic fumes inhalation and near drowning are the common pulmonary causes. The extra-pulmonic causes are systemic sepsis, non-cardiogenic shock, severe trauma, pancreatitis, drug overdose and multiple blood transfusions [43]. Signs and symptoms are dyspnea, cyanosis, tachypnea and hypoxemia mimicking those of 


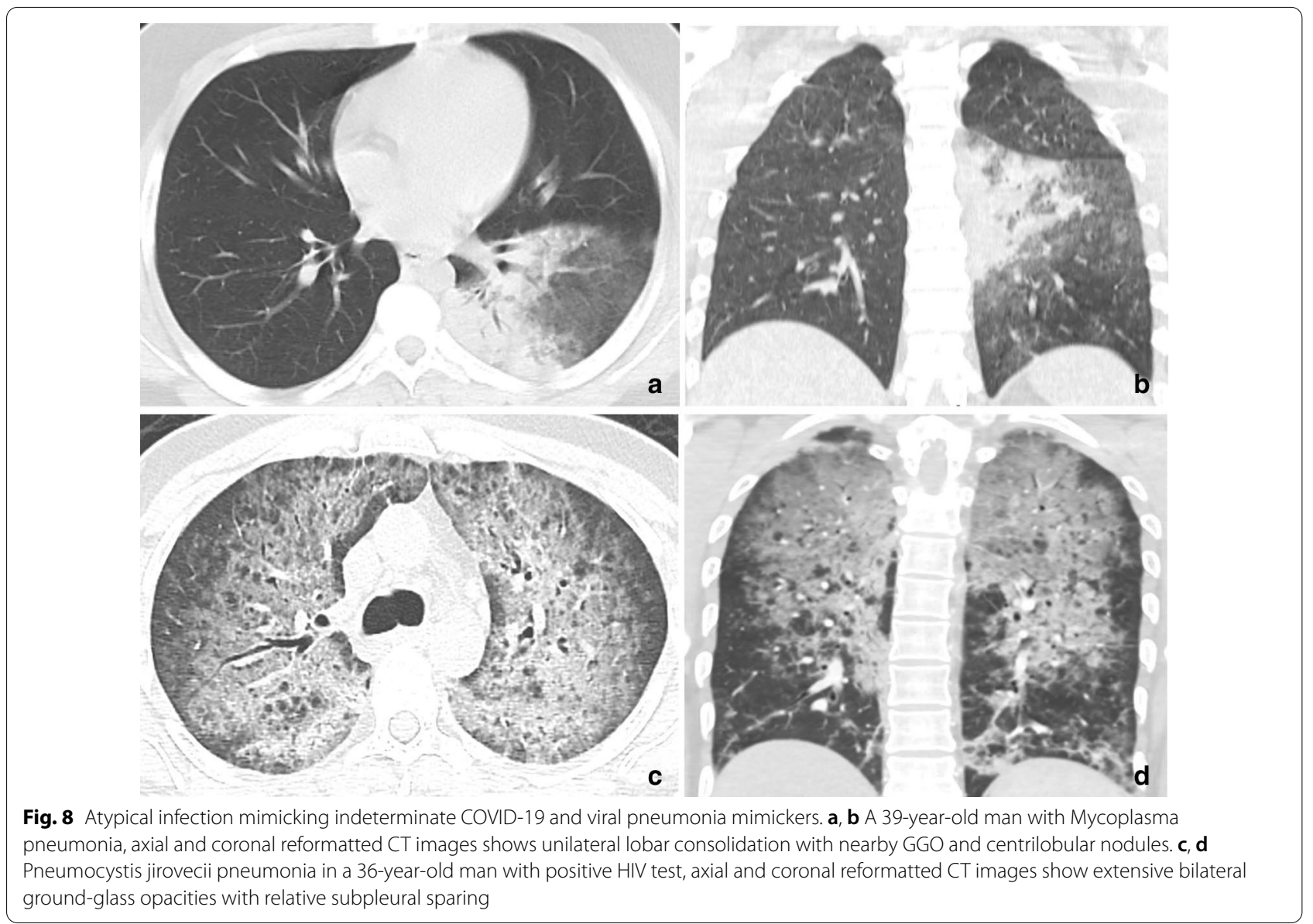

cardiogenic pulmonary edema. Similar to COVID-19, CT features in extra-pulmonary ARDS are bilateral GGO and consolidations distributed peripherally and mainly in the dependent parts of the lung (Fig. 9) [42]. In pulmonary ARDS, the distribution of lung changes is more likely to be asymmetrical, with mixed GGO and non-dependent consolidation [43]. Pleural effusion and bronchial dilatation within GGO are equally common to both types of ARDS.

\section{Hypersensitivity pneumonia (HP)}

$\mathrm{HP}$ is a diffuse parenchymal lung disease caused by inhalation and sensitization to a long list of aerosolized antigens [44]. HP is often categorized into acute, subacute and chronic stages. Acute HP symptoms range from dyspnea, cough and myalgia to extensive pulmonary edema, while subacute HP symptoms are lesser and more insidious and may be associated with cyanosis, fatigue and weight loss $[44,45]$. CT in acute HP may be normal or show diffuse ground-glass opacity. In subacute HP, CT often shows GGO similar to COVID19 though the presence of faint centrilobular nodules and air trapping more in the upper and middle lung zones are characteristic features for subacute HP that help in differentiation between both diseases (Fig. 10). Lobular areas of reduced attenuation are often seen in expiratory phase and indicative of air trapping. Sometimes thinwalled cysts $(<15 \mathrm{~mm}$ in diameter) may be found. Additionally, the head-cheese sign is relatively specific for HP and consists of a constellation of GGO, air trapping and normal intervening lung with geographic margins [45]. In chronic HP, fibrotic changes as traction bronchiectasis and honeycombing are found $[31,45]$.

\section{Eosinophilic pneumonia}

An idiopathic disease that usually affects middle age with relative predominance in females and asthmatic patients [46]. Diagnosis of eosinophilic pneumonia is complex and usually based on the association of the respiratory and general manifestations (including shortness of breath, dyspnea and fever) with characteristic laboratory findings as alveolar and blood eosinophilia. In CT, there are typical bilateral non-segmental areas of airspace consolidation (no subpleural sparing) with predominance for the middle and upper lobes (Fig. 10), unlike the lower lobe predominance seen in COVID-19. Less common 


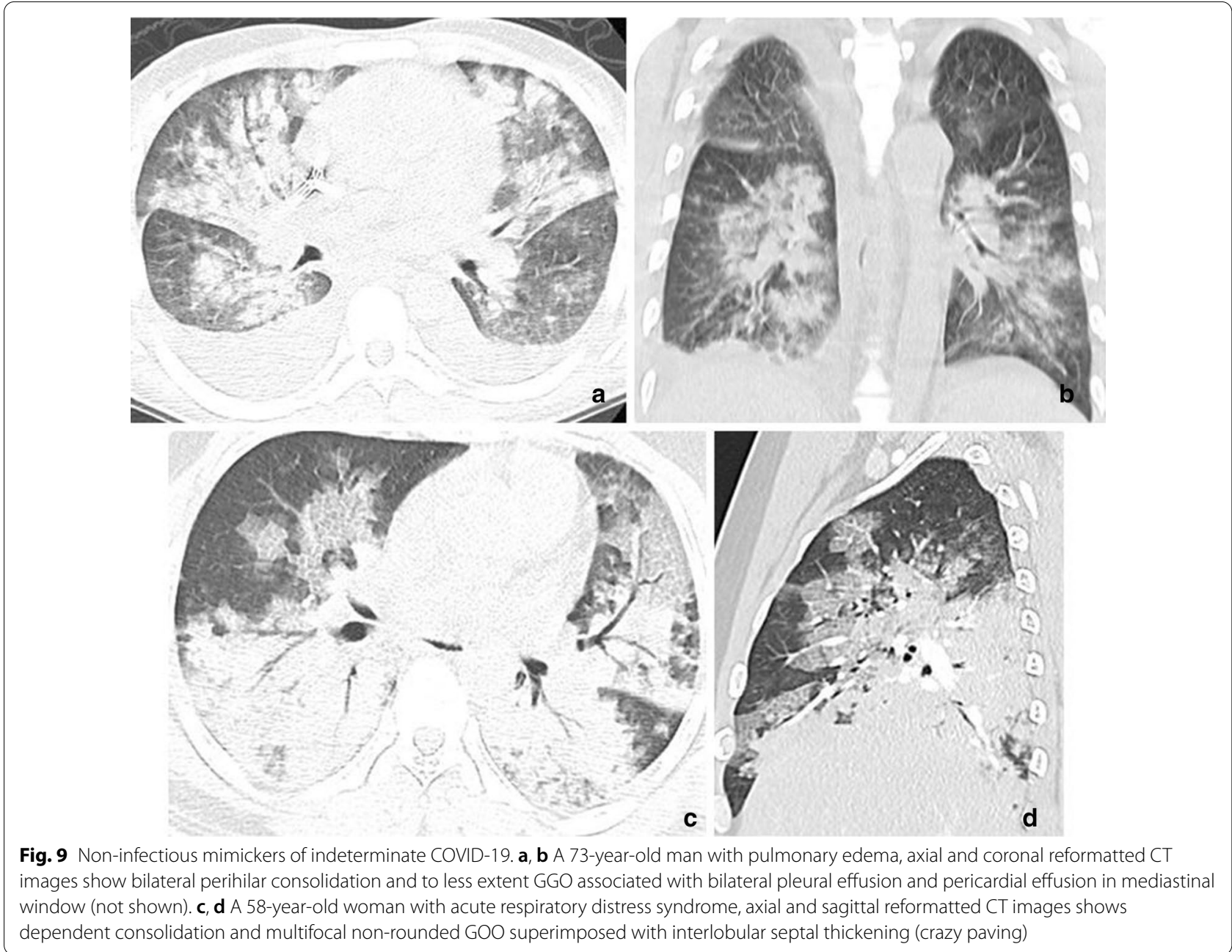

presentations include GGO, lung reticulations and solid pulmonary nodules. Pleural effusion and mediastinal lymphadenopathy may be seen $[42,46]$.

\section{Diffuse alveolar hemorrhage (DAH)}

DAH is a severe and potentially fatal condition. Clinical history is important in diagnosis of DAH and differentiation from COVID-19. The presence of anemia, thrombocytopenia, coagulopathy, hemoptysis, collagen-vascular disease, pulmonary-renal syndromes (Wegener granulomatosis and Goodpasture syndrome) or recent bone marrow transplantation raises the possibility of DAH [47]. On CT, DAH often shows diffuse, patchy or lobular GGO and consolidation with perihilar and dependent distribution. A "crazy-paving" pattern occurs resulting from associated interlobular septal thickening (Fig. 11). DAH usually resolves within 10 days to 2 weeks [42, 47].

\section{Pulmonary alveolar proteinosis (PAP)}

PAP is a rare lung disorder with three clinical forms: autoimmune, secondary and congenital. It is characterized by periodic acid Schiff stain positive material within the alveoli. CT shows areas of "crazy-paving" pattern that is more common in patients with autoimmune PAP than in secondary PAP (Fig. 12). Subpleural sparing, geographic distribution and lower lung predominance were also more frequent in autoimmune PAP [48]. Air space disease with patchy areas of parenchymal abnormalities may also reproduce a COVID-19 appearance; however, perihilar distribution in PAP is a differentiating point. Pulmonary nodules, pleural effusion and lymphadenopathy are not a feature of PAP but if present, then a superimposed infection should be considered. Clinically, PAP is different from COVID-19 as patients often present with low-grade fever, progressive exertional dyspnea and cough; however, patients may experience respiratory failure and require mechanical ventilation, which is an unusual but recognized complication [49]. 

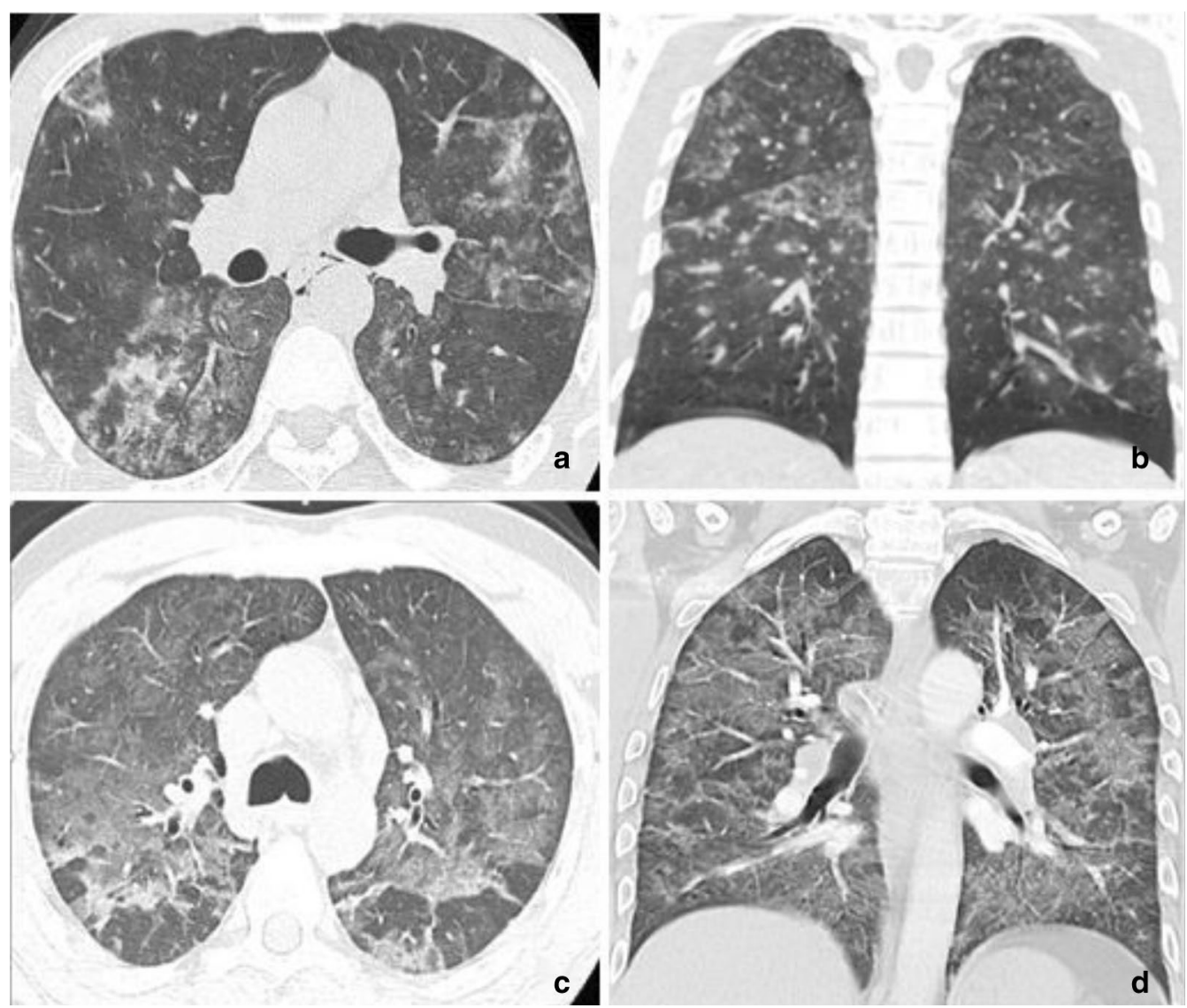

Fig. 10 Non-infectious mimickers of indeterminate COVID-19. a, b A 33-year-old bird breeder with subacute hypersensitivity pneumonitis, axial and coronal reformatted CT images shows patchy or diffuse bilateral ground-glass opacities associated with poorly defined centrilobular nodules and lobular areas of reduced attenuation indicative of air trapping. c, d A 38-year-old man with acute eosinophilic pneumonia, axial and coronal reformatted CT images shows multifocal non-rounded GOO associated with inter- and intralobular septal thickening and thickened bronchovascular bundles

\section{Interstitial lung abnormality (ILA)}

ILA is increasingly recognized, and evolving descriptive term often encompasses different nondependent pulmonary abnormalities detected on chest $\mathrm{CT}$ and affecting more than $5 \%$ of any lung zone. It is observed in patients with no prior or established history of interstitial lung disease, in $4 \%-9 \%$ of smokers and $2 \%-7 \%$ of nonsmokers. Clinically, ILA manifested by chronic cough and shortness of breath, reduced total lung capacity and reduced exercise capacity [50-52]. It often progresses to a subclinical or early phase of lung fibrosis. Several nonfibrotic and fibrotic CT patterns have been described as ILA, including ground-glass opacities with or without reticulation, mosaic attenuation, centrilobular nodularity, 


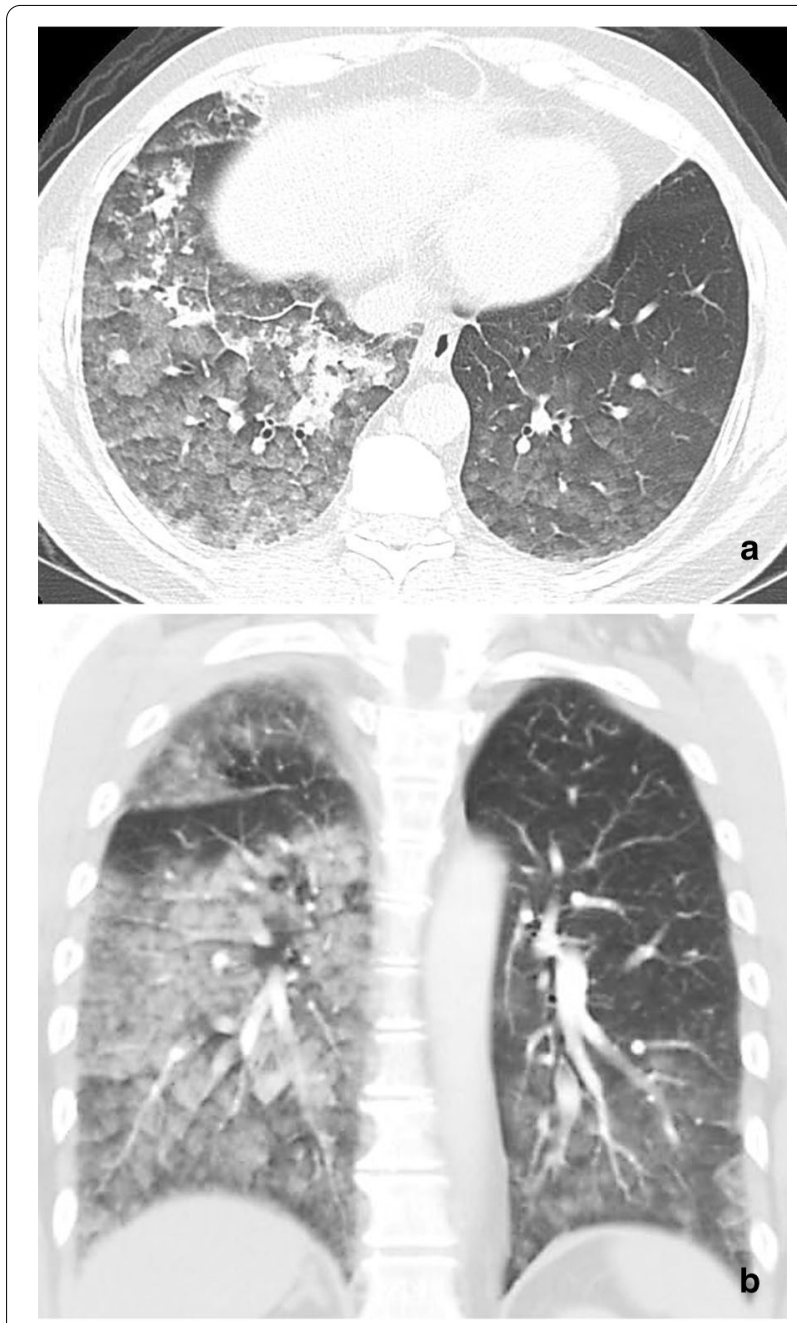

Fig. 11 Non-infectious mimickers of indeterminate COVID-19. A 63-year-old man with diffuse alveolar hemorrhage secondary to thrombolytic therapy for myocardial infarction. $\mathbf{a}, \mathbf{b}$ axial and coronal reformatted HRCT images show asymmetric bilateral patchy areas of GGO with small areas of consolidation

honeycombing nonemphysematous cysts and traction bronchiectasis [50].

\section{Clinical mimickers of COVID-19 with atypical CT chest features}

The clinical course of viral or bacterial pneumonia may simulate COVID-19; however, CT features such as perihilar predominance, centrilobular / tree in pud nodules,

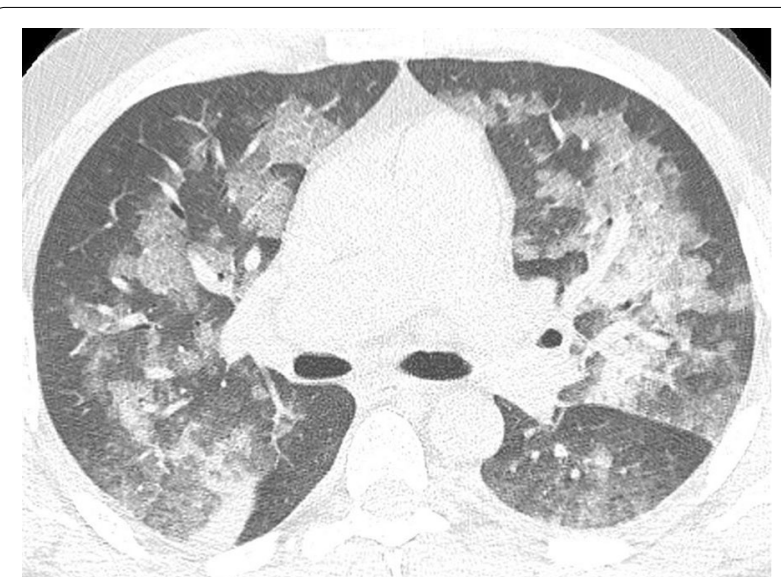

Fig. 12 Non-infectious mimickers of indeterminate COVID-19. Pulmonary alveolar proteinosis proved by bronchoalveolar lavage (BAL) in a 38-year-old male smoker, axial CT image shows asymmetric bilateral patchy areas of GGO superimposed with interlobular septal thickening and crazy paving pattern, right-side fissural effusion is also noted

pleural effusion and lymphadenopathy are in favor of viral pneumonia rather than COVID-19. For example, RSV (respiratory syncytial virus) pneumonia was noted to be common in adults who require ICU admission in the winter season; unlike COVID-19, it shows an airway centric distribution, with bronchial wall thickening and tree in bud opacities, consolidation may or may not occur [53]. Varicella-zoster, measles and mumps typically present with multifocal centrilobular nodular infiltration and less commonly GGO (Fig. 13a) [23, 54]. In contrary to COVID-19, hilar lymphadenopathy and pleural effusion are common association with measles. Segmental or lobar consolidation with cavitation is a sign of bacterial pneumonia (Fig. 13b) or coexistence infection with COVID-19 (Fig. 13c). This common radiological appearance mostly cannot be used to predict the causative organism [53].

\section{Conclusion}

A broad spectrum of pulmonary conditions demonstrates imaging features that mimic those of COVID-19 and are difficult to differentiate from it. Awareness of these conditions, careful radiologic analysis and attention to the clinical data are required to prevent an 


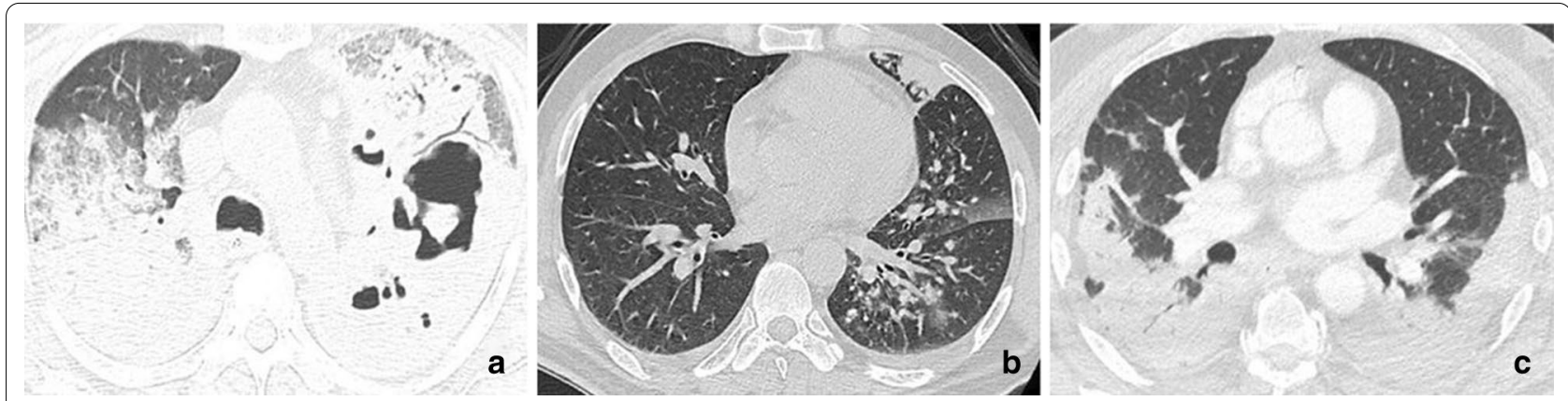

Fig. 13 Atypical features for COVID-19. a A 47-year-old man with respiratory syncytial virus (RSV) pneumonia, axial HRCT image shows left pulmonary tree-in-bud opacities with centrilobular nodules, nearby patches of GGO and segmental consolidation anteriorly. b A 58-year-old woman with methicillin-resistant staphylococcus aureus (MRSA) pneumonia, HRCT shows bilateral consolidation with areas of GGO superimposed with crazy paving and cavitation on the left side. c A 67-year-old woman admitted to ICU with positive RT-PCR for COVID-19, axial HRCT show bilateral consolidation without significant GGO that was suggestive of coexisted bacterial infection. The causative organism of secondary infection was proved to be staphylococcus aureus, which is one of the commonest causes of hospital acquired infection

erroneous diagnosis that could potentially adversely impact management and patients' outcome. A correct diagnosis of these conditions may prevent unnecessary hospitalization and reduce strict quarantine measures for all suspected patients that hold significant pressure on healthcare providers and medical infrastructure.

\section{Supplementary information}

Supplementary information accompanies this paper at https://doi. org/10.1186/s13244-020-00956-6.

Additional file 1. Three-dimensional semitransparent volume-rendered reconstructions show the peripheral and basal distribution of the groundglass opacities across both lungs for 54 years old man with COVID-19 positive RT-PCR test

\section{Abbreviations}

AFOP: Acute fibrinous organizing pneumonia; AIP: Acute interstitial pneumonia; ARDS: Acute respiratory distress syndrome.; COP: Cryptogenic organizing pneumonia; COVID-19: Coronavirus disease 2019: DAD: Diffuse alveolar damage; GGO: Ground-glass opacity; HRCT: High-resolution computed tomography; ICU: Intensive care unit; LDH: Lactate dehydrogenase; MERS: Middle East respiratory syndrome; OP: Organizing pneumonia; PJP: Pneumocystis jiroveci pneumonia; RT-PCR: Reverse transcription-polymerase chain reaction; SARS: Severe acute respiratory syndrome; SARS-CoV-2: Severe acute respiratory syndrome coronavirus 2 .

\section{Authors' contributions}

All nine authors have read and approved the manuscript. AHE: Review concept and design. Partial writing of the manuscript. NMB: Partial writing of the manuscript. Language and grammar editing. DB: Partial writing of the manuscript. BNG: Partial writing of the manuscript. RMA: Collection of cases and preparation figures. MZ: Collection of cases and preparation figures. SAA Partial writing of the manuscript, preparation of tables. AE: Revision of clinical information in the manuscript. AEM: Supervision of the work. Final revision of the manuscript.

\section{Funding}

The authors state that this work has not received any funding.
Availability of data and materials

All data generated during this study are included inthis published article.

\section{Ethics approval and consent to participate}

Institutional Review Board approval was not required because our work is considered as a review article. Written informed consent was not required for this study because our work is considered as a review article / pictorial essay. No human experimentation was done.

\section{Consent for publication}

The authors hereby transfer, assign or otherwise convey all copyright ownership to the insight into imaging journal in the event that such work is published in that Journal.

\section{Competing interests}

The authors declare that they have no conflict of interest.

\section{Author details}

${ }^{1}$ Department of Radiology, Mansoura University, Elgomhoria St., Mansoura 35516, Egypt. ${ }^{2}$ Department of Radiology, Farwaniya Hospital, Al Farwaniyah, Kuwait. ${ }^{3}$ Department of Radiology, Cairo University, Giza, Egypt.

${ }^{4}$ Pulmonary Medicine Department, Mansoura University, Mansoura, Egypt.

${ }^{5}$ Pulmonary Medicine Department, Loewenstein Lung Center, Löwenstein, Germany.

Received: 12 October 2020 Accepted: 14 December 2020 Published online: 03 February 2021

\section{References}

1. Zhu N, Zhang D, Wang W et al (2020) A novel coronavirus from patients with pneumonia in China, 2019. N Engl J Med 382(8):727-733. https:// doi.org/10.1056/NEJMoa2001017

2. World Health Organization. WHO Director-General's opening remarks at the media briefing on COVID-19; Available from: https://www.who.int/ $\mathrm{dg} /$ speeches/detail/who-director-general-s-opening-remarks-at-themedia-briefing-on-covid-19---11-march-2020 [accessed 11 April 2020].

3. World Health Organization. Coronavirus Disease 2019 (COVID-19) weekly epidimiological report-November 10, 2020. Available from: https://www. who.int/emergencies/diseases/novel-coronavirus-2019/situation-reports. Accessed 14th November 2020.

4. Fang $Y$, Zhang $H$, Xie J et al (2020) Sensitivity of Chest CT for COVID19: Comparison to RT-PCR. Radiology 296(2):E115-E117. https://doi. org/10.1148/radiol.2020200432 
5. Xie X, Zhong Z, Zhao W, Zheng C, Wang F, Liu J (2020) Chest CT for typical 2019-nCoV pneumonia: relationship to negative RT-PCR testing. Radiology 296(2):E41-E45. https://doi.org/10.1148/radiol.20202003439

6. Bernheim A, Mei X, Huang M et al (2020) Chest CT findings in coronavirus disease-19 (COVID-19): relationship to duration of infection. Radiology 295(3):200463. https://doi.org/10.1148/radiol.2020200463

7. Pan F, Ye T, Sun P et al (2019) Time course of lung changes on chest CT during recovery from novel coronavirus (COVID-19) pneumonia. Radiology 295(3):715-721

8. Ai T, Yang Z, Hou H et al (2019) Correlation of chest CT and RT-PCR testing in coronavirus disease (COVID-19) in China: a report of 1014 cases. Radiology 2020:200642. https://doi.org/10.1148/radiol.2020200642

9. Bai HX, Hsieh B, Xiong Z et al (2020) Performance of radiologists in differentiating COVID-19 from viral pneumonia on chest CT. Radiology 200823. https://doi.org/10.1148/radiol.2020200823.

10. Guan WJ, Ni ZY, Hu Y et al (2020) Clinical characteristics of coronavirus disease 2019 in China. N Engl J Med 382(18):1708-1720. https://doi. org/10.1056/NEJMoa2002032

11. Simpson S, Kay FU, Abbara S et al (2020) Radiological Society of North America Expert Consensus Statement on Reporting Chest CT Findings Related to COVID-19. Endorsed by the Society of Thoracic Radiology, the American College of Radiology, and RSNA. Radiology Cardiothorac Imaging. https://doi.org/10.1148/ryct.2020200152

12. Chen N, Zhou M, Dong X et al (2020) Epidemiological and clinical characteristics of 99 cases of 2019 novel coronavirus pneumonia in Wuhan, China: a descriptive study. Lancet 395(10223):507-513. https://doi. org/10.1016/S0140-6736(20)30211-7

13. Tan L, Wang $Q$, Zhang $D$ et al (2020) Lymphopenia predicts disease severity of COVID-19: a descriptive and predictive study. Signal Transduct Target Ther 5(1):1-3

14. Chung M, Bernheim A, Mei X et al (2020) CT imaging features of 2019 novel coronavirus (2019-nCoV). Radiology 295(1):200230. https://doi. org/10.1148/radiol.2020200230

15. Kong W, Agarwal PP (2020) Chest imaging appearance of COVID-19 infection. Radiology Cardiothorac Imaging 2(1):200028

16. Salehi S, Abedi A, Balakrishnan S (2019) Coronavirus disease (COVID-19): a systematic review of imaging findings in 919 patients. AJR Am J Roentgenol 2020:1-7. https://doi.org/10.2214/AJR.20.23034

17. Zhou S, Wang Y, Zhu T, Xia L (2020) CT features of coronavirus disease 2019 (COVID-19) pneumonia in 62 patients in Wuhan, China. AJR Am J Roentgenol 214(6):1-8. https://doi.org/10.2214/AJR.20.22975

18. Wang Y, Dong C, Hu Y et al (2020) Temporal changes of CT findings in 90 patients with COVID-19 pneumonia: a longitudinal study. Radiology 200843. https://doi.org/10.1148/radiol.2020200843.

19. Oikonomou A, Prassopoulos P (2013) Mimics in chest disease: interstitial opacities. Insights Imaging 4(1):9-27

20. Zhao W, Zhong Z, Xie X, Yu Q, Liu J (2020) Relation between chest CT findings and clinical conditions of coronavirus disease (COVID-19) pneumonia: a multicenter study. AJR Am J Roentgenol 214(5):1072-1077

21. Leonard-Lorant I, Delabranche X, Severac F et al (2020) Acute pulmonary embolism in COVID-19 patients on CT angiography and relationship to D-dimer levels. Radiology 201561

22. Song F, Shi N, Shan F et al (2020) Emerging 2019 novel coronavirus (2019nCoV) pneumonia. Radiology 295(1):200274. https://doi.org/10.1148/ radiol.2020200274

23. Koo HJ, Lim S, Choe J, Choi SH, Sung H, Do KH (2018) Radiographic and CT features of viral pneumonia. Radiographics 38(3):719-739. https://doi. org $/ 10.1148 / \mathrm{rg} .2018170048$

24. Marcos MA, Esperatti M, Torres A (2009) Viral pneumonia. Curr Opin Inf Dis 22(2):143-147. https://doi.org/10.1097/QCO.0b013e328328cf65

25. Kim MC, Kim MY, Lee HJ et al (2016) CT findings in viral lower respiratory tract infections caused by parainfluenza virus, influenza virus and respiratory syncytial virus. Medicine (Baltimore) 95(26):e4003. https://doi. org/10.1097/MD.0000000000004003

26. Marchiori E, Zanetti G, $D^{\prime}$ Ippolito G et al (2011) Swine-origin influenza A (H1N1) viral infection: thoracic findings on CT. AJR Am J Roentgenol 196(6):W723-W728. https://doi.org/10.2214/AJR.10.5109

27. Al-Tawfiq JA, Zumla A, Memish ZA (2014) Coronaviruses: severe acute respiratory syndrome coronavirus and Middle East respiratory syndrome coronavirus in travelers. Curr Opin Inf Dis 27(5):411-417. https://doi. org/10.1097/QCO.0000000000000089
28. Lee JW, Lee KS, Lee HY et al (2010) Cryptogenic organizing pneumonia: serial high-resolution CT findings in 22 patients. AJR Am J Roentgenol 195(4):916-922. https://doi.org/10.2214/AJR.09.3940

29. Zare Mehrjardi M, Kahkouee S, Pourabdollah M (2017) Radio-pathological correlation of organizing pneumonia (OP): a pictorial review. Br J Radiol 90(1071):20160723. https://doi.org/10.1259/bjr.20160723

30. Assayag D, Elicker BM, Urbania TH et al (2014) Rheumatoid arthritis-associated interstitial lung disease: radiologic identification of usual interstitial pneumonia pattern. Radiology 270(2):583-588. https://doi.org/10.1148/ radiol.13130187

31. Ferguson EC, Berkowitz EA (2012) Lung CT: part 2, the interstitial pneumonias?? Clinical, histologic, and CT manifestations. AJR Am J Roentgenol 199(4):W464-W476. https://doi.org/10.2214/AJR.10.7309

32. Rossi SE, Erasmus JJ, McAdams HP, Sporn TA, Goodman PC (2000) Pulmonary drug toxicity: radiologic and pathologic manifestations. Radiographics 20(5):1245-1259. https://doi.org/10.1148/radiographics.20.5.g00se 081245

33. Rosenow EC III, Myers JL, Swensen SJ, Pisani RJ (1992) Drug-induced pulmonary disease: an update. Chest 102(1):239-250

34. Sakao S, Tatsumi K (2012) Molecular mechanisms of lung-specific toxicity induced by epidermal growth factor receptor tyrosine kinase inhibitors. Oncol Lett 4(5):865-867. https://doi.org/10.3892/ol.2012.872

35. Mueller-Mang C, Grosse C, Schmid K, Stiebellehner L, Bankier AA (2007) What every radiologist should know about idiopathic interstitial pneumonias. Radiographics 27(3):595-615

36. Choi SH, Huh JW, Hong SB et al (2015) Clinical characteristics and outcomes of severe rhinovirus-associated pneumonia identified by bronchoscopic bronchoalveolar lavage in adults: comparison with severe influenza virus-associated pneumonia. J Clin Virol 62:41-47. https://doi. org/10.1016/j.jcv.2014.11.010

37. Nambu A, Ozawa K, Kobayashi N, Tago M (2014) Imaging of communityacquired pneumonia: Roles of imaging examinations, imaging diagnosis of specific pathogens and discrimination from noninfectious diseases. World J Radiol 6(10):779-793. https://doi.org/10.4329/wjr.v6.i10.779

38. Miyashita N, Sugiu T, Kawai Y et al (2009) Radiographic features of Mycoplasma pneumoniae pneumonia: differential diagnosis and performance timing. BMC Med Imaging 9:7. https://doi.org/10.1186/1471-2342-9-7

39. Hardak E, Brook O, Yigla M (2010) Radiological features of pneumocystisjirovecii pneumonia in immunocompromised patients with and without AIDS. Lung 188(2):159-163

40. Kanne JP, Yandow DR, Meyer CA (2012) Pneumocystis jirovecii pneumonia: high-resolution CT findings in patients with and without HIV infection. AJR Am J Roentgenol 198(6):W555-W561

41. Assaad S, Kratzert WB, Shelley B, Friedman MB, Perrino Jr A (2018) Assessment of pulmonary edema: principles and practice. J Cardiothorac Vasc Anesth 32(2):901-914. https://doi.org/10.1053/j.jvca.2017.08.028

42. Yacoub W, Attia M, Affes M, et al. Ground-glass opacities on chest CT scans: how to deal with them? 2019. European Congress of Radiology 2019.

43. Desai SR, Wells AU, Suntharalingam G, Rubens MB, Evans TW, Hansell DM (2001) Acute respiratory distress syndrome caused by pulmonary and extrapulmonary injury: a comparative CT study. Radiology 218(3):689693. https://doi.org/10.1148/radiology.218.3.r01 mr31689

44. Magee AL, Montner SM, Husain A, Adegunsoye A, Vij R, Chung JH (2016) Imaging of hypersensitivity pneumonitis. Radiol Clin 54(6):1033-1046. https://doi.org/10.1016/j.rcl.2016.05.013

45. Hanak V, Golbin JM, and Ryu JH. Causes and presenting features in 85 consecutive patients with hypersensitivity pneumonitis. in Mayo Clinic Proceedings. 2007. Elsevier.

46. Jeong YJ, Kim KI, Seo IJ et al (2007) Eosinophilic lung diseases: a clinical, radiologic, and pathologic overview. Radiographics 27(3):617-637. https ://doi.org/10.1148/rg.273065051

47. Castañer E, Alguersuari A, Gallardo X, Andreu M, Pallardó Y, Mata JM, Ramírez J (2010) When to suspect pulmonary vasculitis: radiologic and clinical clues. Radiographics 30(1):33-53

48. Kroll RR, Kumar S, Grossman RF, Price C, Srigley JR (2016) Rare presentation of pulmonary alveolar proteinosis causing acute respiratory failure. Can Respir J. https://doi.org/10.1155/2016/4064539

49. Akira M, Inoue Y, Arai T et al (2016) Pulmonary fibrosis on high-resolution $\mathrm{CT}$ of patients with pulmonary alveolar proteinosis. AJR Am J Roentgenol 207(3):544-551 
50. Hatabu H, Hunninghake GM, Lynch DA (2019) Interstitial lung abnormality: recognition and perspectives. Radiology 291(1):1-3. https://doi. org/10.1148/radiol.2018181684

51. Washko GR, Hunninghake GM, Fernandez IE et al (2011) Lung volumes and emphysema in smokers with interstitial lung abnormalities. N Engl J Med 364(10):897-906

52. Jin GY, Lynch D, Chawla A et al (2013) Interstitial lung abnormalities in a CT lung cancer screening population: prevalence and progression rate. Radiology 268(2):563-571

53. Miller WT Jr, Mickus TJ, Barbosa E Jr et al (2011) CT of viral lower respiratory tract infections in adults: comparison among viral organisms and between viral and bacterial infections. AJR Am J Roentgenol 197(5):1088-1095

54. Rafat C, Klouche K, Ricard JD et al (2013) Severe measles infection: the spectrum of disease in 36 critically ill adult patients. Medicine (Baltimore) 92(5):257. https://doi.org/10.1097/MD.0b013e3182a713c2

\section{Publisher's Note}

Springer Nature remains neutral with regard to jurisdictional claims in published maps and institutional affiliations.

\section{Submit your manuscript to a SpringerOpen ${ }^{\circ}$ journal and benefit from:}

- Convenient online submission

- Rigorous peer review

- Open access: articles freely available online

- High visibility within the field

- Retaining the copyright to your article

Submit your next manuscript at $\boldsymbol{\nabla}$ springeropen.com 